\title{
Public Perceptions of Food-related Risks: A Cross-national Investigation of Individual and Contextual Influences*
}

\author{
Kelsey D. Meagher \\ University of California, Davis \\ kdmeagher@ucdavis.edu
}

\begin{abstract}
Public concerns about food risks have grown in recent decades in response to many food-related scandals. Despite some evidence that risk concerns vary across societies and risk domains, these variations remain understudied. To address this gap, this paper conducts a multi-level analysis of public concerns about biological and chemi$\mathrm{cal} /$ technical food risks in 26 European countries. Findings confirm previous work on individual predictors of risk concern and suggest that several contextual factors contribute to cross-national variations: aggregate perceptions of risks as unnatural, retail concentration in the food sector, and media coverage. The effect of institutional trust on risk concerns varies substantially across nations. Findings also reveal important differences in public concerns about biological versus chemical/technical food risks, supporting the view that food risk perception is multi-dimensional and complex.
\end{abstract}

\section{INTRODUCTION}

In recent decades, many food-related scandals in Europe have prompted public concerns about food risks. Notable events include the BSE ("mad cow disease") crisis, dioxins in Belgian chickens and eggs (1999), the E. coli outbreak in Germany (2011), and the horse meat scandal (2013). Social scientists have examined the causes and consequences of public food risk perceptions, noting their importance for improving risk management and communication. In part because food is a "credence good," and consumers must rely on experts to

${ }^{*}$ This article has been accepted for publication in the Journal of Risk Research, available online: https://doi.org/10.1080/13669877.2017.1422789. 
evaluate and ensure safety, scholars have focused especially on the role of institutional trust in driving risk concerns (De Jonge et al. 2008). Despite some evidence that risk concerns differ cross-nationally, explanatory mechanisms remain unknown.

National differences in risk concern can result from compositional differences in individual characteristics or country-level forces impacting the entire population. Previous research tends to focus on individual-level explanations, identifying several demographic and ideological predictors of risk concern, for example gender, education, perceived control, and institutional trust (Siegrist and Cvetkovich 2000; Slovic 1987). Less research investigates contextual influences on risk perception, but qualitative studies suggest that the structure of food provisioning systems, divisions of regulatory authority, and media coverage could contribute to national variations by shaping public expectations about risk management (Berg et al. 2005; Kjaernes, Harvey, and Warde 2007). Much of this research examines only a handful of countries, however, raising questions about generalizability. This paper seeks to build on this literature by analyzing contextual influences on food risk concern in 26 European countries.

Another motivation for the paper is to examine varying concerns across risk type. I distinguish between food risks of biological origin (i.e., bacterial pathogens and viruses) and those of chemical or technical origin (i.e., pesticides and biotechnologies). Some evidence suggests that consumers worry less about microbial risks than about chemical/technical risks, which they associate with more severe health problems (Kher et al. 2013). However, most risk perception studies do not compare multiple risks, focusing on only one risk (often genetic modification) or a scale comprising multiple concerns (c.f. Hohl and Gaskell 2008).

Descriptive analysis of Eurobarometer 73.5 suggests that Europeans worry about multiple food risks; $63 \%$ of respondents feel "fairly" or "very worried" about bacterial contamination, $73 \%$ worry about pesticide residues, and $67 \%$ worry about GM food (European Commission 2010b). However, European consumer groups organize far more often against pesticides and genetic modification than against microbial contamination. Why is this so? I analyze public perceptions of chemical/technical risks and biological risks separately to see if differences in the structure of these concerns might help explain their divergent public treatment.

This paper presents a multi-level, cross-national analysis of public concerns about biological and chemical/technical food risks. I analyze variations in concerns by risk type and then construct multi-level models of individual and contextual influences on risk concerns. Data from the Eurobarometer 73.5 (2010) are merged with country-level data from several sources. Results 
indicate substantial cross-national differences in risk concern and suggest that several contextual factors contribute to national variations. Findings also reveal differences in concerns about biological and chemical/technical risks, supporting the view that food risk perception is multi-dimensional and complex.

\section{PUBLIC PERCEPTIONS OF BIOLOGICAL AND CHEMICAL/TECHNICAL FOOD RISKS}

Modern consumers confront numerous food-related risks, including bacterial contaminants, chemical contaminants, biotechnologies, food allergies and sensitivities, and diet-related illnesses. Consumers' concerns involve not only personal health but also concern for the environment, traditional food cultures, and the role of technology in society. Public concerns about food are multidimensional and vary cross-culturally (Hohl and Gaskell 2008; Miles and Frewer 2001).

Some evidence suggests that consumers make cognitive distinctions between biological and chemical food contaminants (Fife-Schaw and Rowe 1996; Miles and Frewer 2001). Individuals generally express greater concern about chemical/technical risks than about microbial risks, associating the former with more serious health consequences and reduced personal control (Kher et al. 2013). The landscape of European social movements also suggests a division in food-related concerns; activists have organized extensively against genetically modification and hormones in food, for example (Ansell, Maxwell, and Sicurelli 2006; Schurman 2014), yet despite several scandals involving biological risks (e.g., BSE and the 2011 German E. coli outbreak), these risks have sparked limited public mobilization.

Few studies directly compare public perceptions of biological and chemical/technical risks; most focus on a single risk, with the literature heavily tilted toward biotechnologies (c.f. Costa-Font and Gil 2009; Marques, Critchley, and Walshe 2015). Among the studies investigating multiple food risks, most include samples from only one or several countries, so little is known about cross-national differences (c.f. Hunt and Frewer 2001; Kher et al. 2013). This paper bridges the gap by analyzing a large survey of attitudes about chemical/technical and biological food risks. Understanding variations in consumer concerns is important for strengthening risk communication and public policy, particularly in supranational regimes like the E.U. where national differences can create thorny governance challenges.

Previous research identifies demographic trends in food-related concerns. 
Women tend to report greater concerns than men, a pattern potentially related to their greater role in household food provisioning (De Jonge et al. 2007; Dosman, Adamowicz, and Hrudey 2001). Some evidence suggests that households with children report greater concerns about food risks (Dosman et al. 2001), but others do not find a significant effect (Miles et al. 2004). Several studies find that education increases confidence about food safety, although the causal mechanism is unclear (Baiardi, Puglisi, and Scabrosetti 2016; De Jonge et al. 2007). Dosman et al. (2001) note that educated people may be more informed and thus more concerned about food risks; however, education may also mitigate elevated concerns by empowering people to feel greater control over food risks. The data in this study allow us to replicate and extend previous work on demographic trends in risk perception.

Perceived personal control is another important influence on risk perception. Individuals generally worry more about involuntary or uncontrollable risks, regardless of the "objective" probability of harm (Renn et al. 1992; Slovic 1987). Some research shows that people fear lifestyle risks (like dietrelated illness) less than technological risks (like genetic engineering), which they believe to be less controllable (Hansen et al. 2003; Sparks and Shepherd 1994). Although some single-country studies do not find a relationship between perceived control and food safety concerns (De Jonge et al. 2007; Frewer, Shepherd, and Sparks 1994), a recent analysis suggests that Europeans who feel confident in their ability to avoid food risks worry less often about such risks (Gaskell, Hohl, and Gerber 2016). It is possible that perceived personal control varies cross-nationally, contributing to population-level differences in risk perception.

- Hypothesis 1: Individuals with greater perceived personal control over food risks report lower levels of risk concern.

The Eurobarometer asks about perceived control regarding several food risks, including chemical contamination, animal cloning and biotechnology, bacterial contamination, and zoonotic diseases. These data allow us to examine whether perceived control varies across risk type. Given previous studies linking technological risks to perceived uncontrollability, I hypothesize the following:

- Hypothesis 2: Individuals feel greater personal control over biological food risks than over chemical/technical food risks.

Institutional trust has been extensively studied in relation to risk perception and social acceptance of new technologies (Poortinga and Pidgeon 2003; 
Slovic 1993). Many scholars believe trust is especially important in modern societies with higher levels of labor specialization and societal interdependence, since interpersonal trust is replaced by more abstract trust in social institutions (Freudenburg 1993; Zucker 1985). The vast majority of citizens in industrialized societies are employed outside of agriculture, so they must rely on institutional actors to protect the safety of their food.

High levels of institutional trust are associated with reduced concerns about multiple hazards (Marques et al. 2015; Slovic 1993). Trust reduces complexity in decision-making, and individuals rely on trust especially when evaluating risks over which they have little knowledge or control (Giddens 1990; Siegrist and Cvetkovich 2000). Trust is widely considered to be multidimensional, although there is some disagreement about its dimensional structure (Poortinga and Pidgeon 2003; Siegrist, Gutscher, and Earle 2005). Crossnational studies suggest two trust dimensions that may be particularly relevant to food risk concerns: institutional competence and honesty (Lobb 2005). The degree to which institutional trust mediates public concerns appears to vary across national context, hazard type, and institutional actor (De Jonge et al. 2008; Lang 2013). For example, consumers generally trust certain food chain actors more than others; multiple studies show high levels of trust in doctors and consumer organizations, less trust in government and the media, and even lower trust in the food industry (Frewer et al. 1996; Lang and Hallman 2005).

Nations have different historical experiences with food crises, which enhance or depress institutional trust. For example, the BSE outbreak impacted European countries unevenly, and national governments handled the crisis in distinct ways (Jasanoff 1997; Kjaernes et al. 2007). Aggregate levels of trust may therefore vary cross-nationally, but based on previous research we expect that trust in all actors is negatively related to food risk concerns.

- Hypothesis 3: Individuals with higher levels of institutional trust are less concerned about food-related risks.

\section{Contextual influences on food risk concerns}

Previous research demonstrates cross-national variations in both risk perception and trust (Berg et al. 2005; Renn and Rohrmann 2013). Hohl and Gaskell (2008) describe a "North-South divide" in food risk concerns; residents of Northern European countries are significantly less likely to worry about food risks than residents of Southern countries. Additionally, institutional trust appears greater in Great Britain and Scandinavia than in Italy, Portugal, and Germany (Kjaernes 2006). Kjaernes et al. (2007) suggest that 
cross-national differences cannot be explained by individual differences but instead point to differing norms and expectations shaped by institutionalized relations between the state, food producers, and consumers.

The literature on technological hazards suggests that their perceived unnaturalness contributes to heightened fears and resistance to new technologies (Sjöberg 2000; Slovic 2013). The perceived unnaturalness of GM food and nanotechnology is often used to explain European opposition to these technologies (Siegrist et al. 2008; Wohlers 2010). Fife-Schaw and Rowe (1996) find that individuals believe that "natural" food hazards are easier to avoid and are better regulated than "unnatural" foods. Variations in concern by risk type and nationality may thus covary with public assessments of "unnaturalness." Biological risks are expected to be perceived as more "natural" than chemical/technical risks, so concerns about biological risks should be unrelated to aggregate concerns about unnaturalness. ${ }^{1}$

- Hypothesis 4: People in societies with higher aggregate perceptions of food risks as unnatural express greater concerns about chemical/technical food risks.

The structure of food provisioning systems varies across Europe in ways that may impact risk perception. The structure of the retail sector, the degree of agricultural self-sufficiency, and the relative prominence of different food markets all impact consumers' choices and the institutional actors they hold responsible for food safety. National reliance on food imports has been suggested to impact consumer risk perceptions; imported foods involve a more geographically dispersed chain of actors, which may stoke consumer anxieties about how their food is produced. Previous research shows that consumers prefer locally produced food, interpreting a product's country-of-origin as a cue for quality and safety (Elliott and Cameron 1994; Hoffmann 2000; Lobb and Mazzocchi 2007). Given this preference, countries reliant on food imports are expected to have higher aggregate concerns about food-related risks.

- Hypothesis 5: Residents of net-food-importing countries have greater concerns about food risk than residents of net-food-exporting countries.

In a study of six European countries, Kjaernes et al. (2007) find that consumers in retail-dominated countries report greater trust in food than countries with more traditional food provisioning systems. In countries where

\footnotetext{
${ }^{1}$ Although I would like to model this effect at both levels (individual and country), questions about unnaturalness appear only in an earlier Eurobarometer (73.1), which precludes an examination of individual attitudes about unnaturalness.
} 
local shops continue to dominate, consumers report more personalized relations with food providers but also increased anxieties about food quality and nutrition. Kjaernes et al. (2007) interpret these results within a modernization framework; as retailers modernize food supply chains, consumers come to trust their standardized processes to deliver safe products. Consumers in countries with traditional, heterogenous markets may not trust food providers to have resources or expertise to enforce strict safety standards. This paper examines whether the trend observed above extends across Europe and helps explain cross-national differences in risk concern.

- Hypothesis 6: Residents of nations with greater retail concentration have lower levels of food risk concern.

Finally, the media plays an important role in drawing public attention to social issues, and public risk perceptions are influenced by the media's interpretive frames (Lockie 2006). Media coverage elevates the perceived magnitude of risk posed by various foods and diminishes institutional trust (Henderson et al. 2012, 2014). Therefore, we expect increased public awareness of food risks, as well as heightened public concerns, in places with greater media coverage of food risks.

- Hypothesis 7: Higher levels of media coverage about food safety are associated with increased concerns about food risks.

\section{DATA AND METHODS}

\section{Data}

Individual-level data come from a Eurobarometer survey on food-related risks conducted in June 2010 (European Commission 2010b). A multistage random sampling procedure was used to collect nationally representative data from 26,691 individuals in 27 European countries. All respondents are 15 years or older and residents of the country in which they were interviewed. Eurobarometer 73.5 collected separate samples for Northern Ireland and East Germany, and the subsamples are preserved in the analysis. Observations from Malta are excluded due to missing data on key variables, yielding a final sample of 26,191 individuals nested in 28 nations and regions. I address missing data using multiple imputation by chained equations (White, Royston, 
and Wood 2011). ${ }^{2}$ Descriptive statistics for all variables appear in Tables 1 and 2 .

Table 1: Descriptive Statistics for Individual-level variables

\begin{tabular}{lcccccc}
\hline Variable & $\mathrm{N}$ & Missing & Mean & SD & Min & Max \\
\hline Female & 26111 & 0 & 0.538 & 0.499 & 0 & 1 \\
Married & 26053 & 58 & 0.522 & 0.5 & 0 & 1 \\
Children & 26111 & 0 & 0.272 & 0.445 & 0 & 1 \\
Education & 25633 & 478 & 17.176 & 7.033 & 0 & 80 \\
Student & 26111 & 0 & 0.084 & 0.277 & 0 & 1 \\
Manager/professional & 26111 & 0 & 0.214 & 0.41 & 0 & 1 \\
Age & 26111 & 0 & 47.844 & 18.296 & 15 & 97 \\
Difficulty paying bills & 25583 & 528 & 0.118 & 0.322 & 0 & 1 \\
Urban & 26074 & 37 & 0.646 & 0.478 & 0 & 1 \\
Perceived personal control & & & & & & \\
$\quad$ Biological risks & 25474 & 637 & 2.378 & 0.77 & 1 & 4 \\
$\quad$ Chemical risks & 25335 & 776 & 2.152 & 0.776 & 1 & 4 \\
Actor-specific trust & & & & & & \\
$\quad$ EU institutions & 24363 & 1748 & 2.675 & 0.749 & 1 & 4 \\
$\quad$ National government & 25402 & 709 & 2.438 & 0.856 & 1 & 4 \\
$\quad$ Farmers & 25381 & 730 & 2.638 & 0.787 & 1 & 4 \\
$\quad$ Manufacturers & 25487 & 624 & 2.252 & 0.811 & 1 & 4 \\
$\quad$ Retails & 25565 & 546 & 2.184 & 0.806 & 1 & 4 \\
$\quad$ Environmental orgs & 25067 & 1044 & 2.837 & 0.737 & 1 & 4 \\
Consumer orgs & 25185 & 926 & 2.9 & 0.716 & 1 & 4 \\
$\quad$ Media & 25608 & 503 & 2.481 & 0.801 & 1 & 4 \\
General institutional trust & 24646 & 1465 & 2.286 & 0.921 & 1 & 4 \\
Media coverage & 11960 & 14151 & 2.949 & 1.197 & 1 & 5 \\
\hline
\end{tabular}

\footnotetext{
${ }^{2}$ Media coverage is the only predictor with substantial missingness (54.2\%). However, this data is mostly missing at random because half of the sample was randomly selected to receive this question. Of the remaining predictors, only two have more than $5 \%$ missing: trust in E.U. institutions $(6.9 \%)$ and institutional performance (5.7\%). Missing data are imputed using all individual predictors from the analytical model, after which imputed values of the outcome variables are deleted (Von Hippel 2007). Following Graham, Olchowski, and Gilreath (2007), I perform 40 imputations to improve the efficiency and replicability of estimates. The imputed analyses are replicated with listwise deletion as a robustness check, and the findings are substantively similar. Reported results use the imputed data; the listwise deletion results are available upon request.
} 
Dependent variables: Concerns about biological and chemical/technical food risks

The two outcomes derive from 17 questions about consumer concerns about food-related risks. Response options are reverse-coded so higher values reflect greater concern; responses range from $1=$ "Not at all worried" to 4 $=$ "Very worried." The outcome concerns about biological risks is composed of three items: concerns about (1) bacterial contamination, (2) new animal viruses, and (3) BSE. I construct a scale from the mean score over the three items (Cronbach's $\alpha=.79$ ). Similarly, the outcome concerns about chemical/technical risks is a scale constructed from the mean score over eight items: worries about (1) GM food, (2) food additives, (3) pesticide residues, (4) antibiotics or hormones in meat, (5) chemical pollutants (6) chemicals in food packaging, (7) animal cloning, and (8) nanoparticles (Cronbach's $\alpha=.91$ ). ${ }^{3}$ As shown in Table 2, the outcome measures are strongly correlated across the entire sample, with a Pearson's correlation coefficient of .75. However, the correlation between concerns about chemical/technical and biological food risks varies cross-nationally, ranging from .62 in Sweden to .82 in Portugal.

In general, Europeans worry significantly more about chemical/technical risks $($ mean $=2.81)$ than biological risks $($ mean $=2.66 ; t=3.33, p<.01){ }^{4}$ Within national subsamples, however, levels of concern vary. In 24 of the subsamples, people worry more about chemical/technical than biological risks, but in Lithuania concerns do not differ significantly across risk type, and in three other places (Slovakia, Northern Ireland, and the Czech Republic) people worry more about biological risks than chemical/technical ones. Additionally, the gap between concerns over biological and chemical/technical risks varies cross-nationally, with French respondents reporting the greatest gap between risk types. Figure 1 displays the mean scores for both outcomes by nation, and Figure 2 displays the national gaps between biological and chemical/technical risk concerns. These variations suggest substantial differences in how Europeans understand food-related risks.

\footnotetext{
${ }^{3}$ The remaining six "food worry" items are excluded because they represent conceptually distinct concerns about diet (e.g., weight gain) and ethics (e.g., animal welfare).

${ }^{4}$ With this and other descriptive statistics in the paper, the recommended poststratification weights are applied. For descriptive statistics of individual subsamples, a post-stratification weight is applied to adjust for gender, age, region, and size of locality within each nation. For descriptive statistics of Europe as a whole, another weight is applied to correct for the fact that national samples are similar sizes despite being drawn from populations of vastly different sizes. This weight ensures that nations are represented within Europe according to their population size and includes all of the lower-level weighting factors.
} 


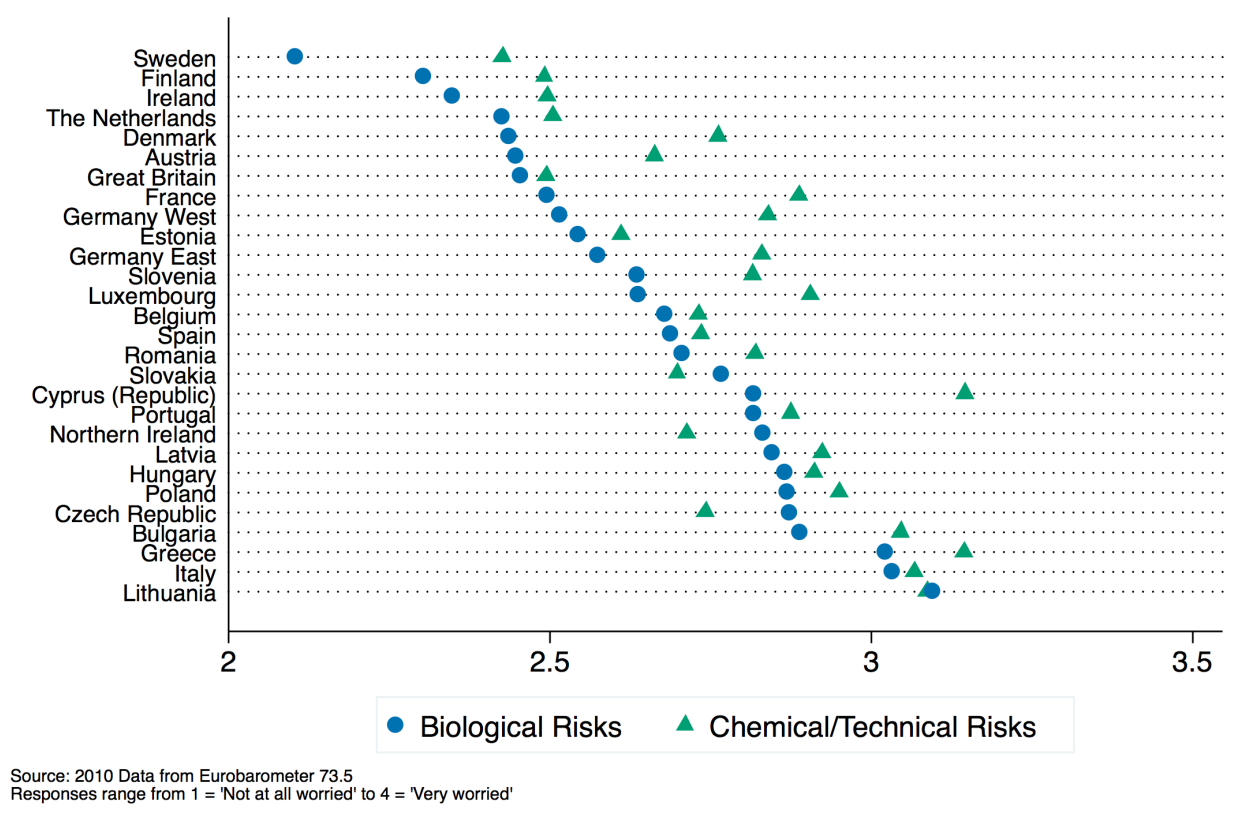

Figure 1: Mean Concerns about Food-related Risks

\section{Individual-level independent variables}

Perceived personal control is represented by two variables. Control over chemical/technical risks comes from two questions asking respondents to rate their confidence in being able to avoid "possible risks from chemical contamination of foods" and "possible risks from new technologies such as animal cloning and nanotechnology." Responses range from $1=$ "Not at all confident" to $4=$ "Very confident." The measure is created from the mean of the two responses (Cronbach's $\alpha=.77$ ). Similarly, control over biological risks is a scale created from two questions asking respondents to rate their confidence in their ability to avoid "possible risks from bacterial contamination of foods" and "possible risks from animal infections or diseases which could be transmitted to humans" (Cronbach's $\alpha=.71$ ).

Institutional trust is represented by a general evaluation of institutional performance as well as separate evaluations of different actors' honesty. Following Kjaernes et al. (2007), I use a measure of general optimism about whether food safety has improved in recent years as an indicator for institutional performance. This measure represents respondents' general evaluation of all the institutions responsible for protecting food safety. The measure asks 


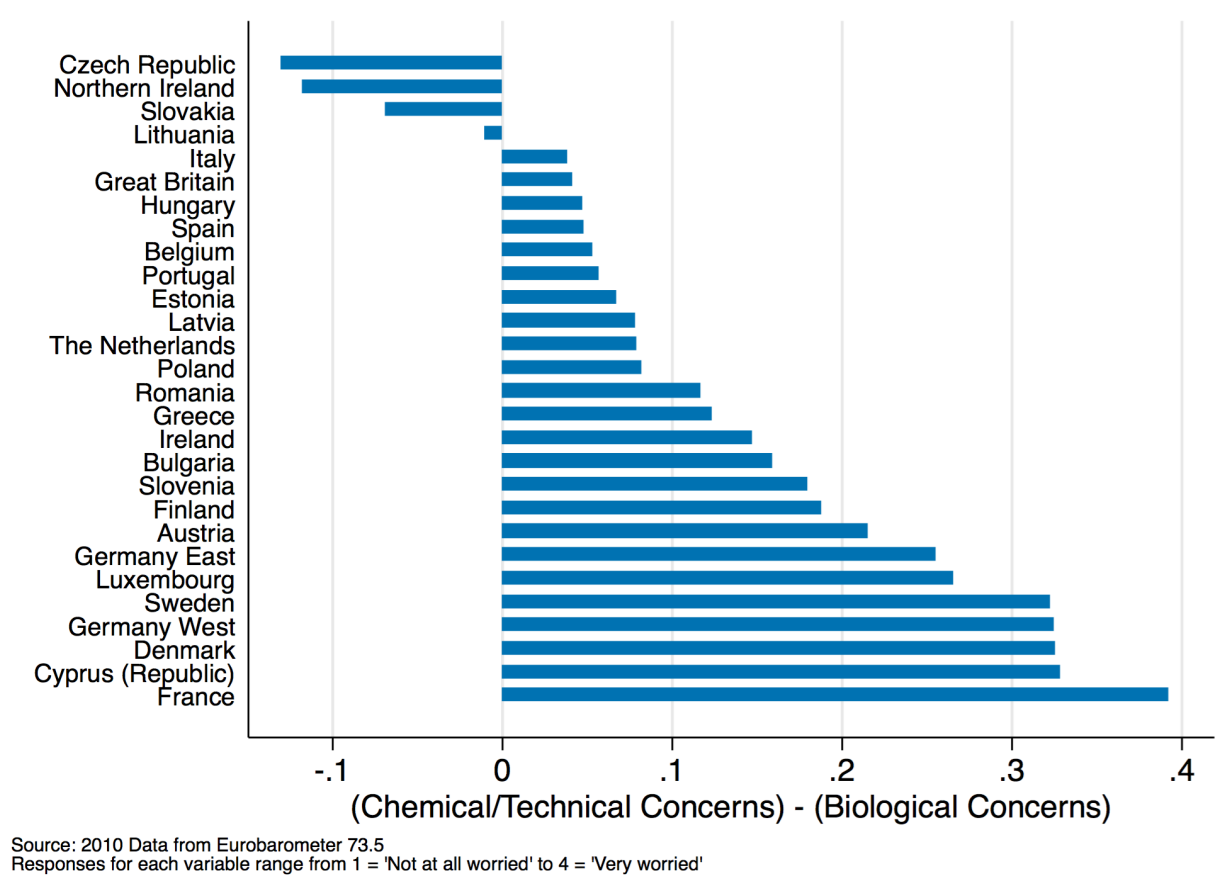

Figure 2: Difference in Mean Concerns about Biological and Chemical/Technical Food Risks

respondents if they agree that "food today is safer compared to ten years ago" (responses range from $1=$ "totally disagree" to $4=$ "totally agree"). Evaluations of institutional honesty are taken from a series of questions asking respondents to imagine that "a serious food risk were found in a food you eat regularly" and to report their confidence in different actors to "give you accurate information about this risk" (from $1=$ "Not at all confident" to $4=$ "Very confident"). Evaluations of eight actors are included in the analysis: European institutions, the respondent's own national government, farmers, food manufacturers, food retailers, environmental organizations, consumer organizations, and the media.

Media coverage of food-related risks represents one of the contextual factors in the analysis and is the only such factor to be measured at the individuallevel. (See below for the remaining contextual measures.) Media coverage comes from a question asking respondents the last time they saw a media story claiming that a food may be unsafe. Response options include $1=$ "never," 2 = "longer than six months ago," 3 = "within the past six months," 
$4=$ "within the past month," and $5=$ "within the last 7 days." Higher values indicate more recent exposure to media coverage of food-related risks. In the analysis, media coverage is mean-centered and included with the country means to explore whether the effect is driven by individual- or country-level processes.

Consistent with previous research, models include several control variables. Gender and marital status are included as binary variables (female $=1$; married $=1)$. Education is represented as the age at which respondents stopped full-time education; responses range from 2-80 years. Current students are coded 0 and marked with a dummy variable. Models also include age (in years) and the presence of children in the household $(1=$ yes, $0=$ no). Controlling for social class is complicated by the lack of income measures. Instead, I use two other variables to represent social class: occupational status $(1=$ manager or professional, $0=$ all others) and whether the respondent had difficulties paying bills last year $(1=$ most of the time, $0=$ occasionally to never $)$. Urban residence is measured as a dummy variable $(1=$ lives in a town, $0=$ lives in a rural area or village).

\section{Country-level independent variables}

Aggregate perceptions of food risks as unnatural are taken from the Eurobarometer 73.1, which was conducted in January and February 2010 using the same methods as the microdata in this study (European Commission 2010a). The item asks respondents whether they agree that GM food is "fundamentally unnatural," with response options ranging from $1=$ "Totally disagree" to $4=$ "Totally agree." The mean score for each nation is calculated using the recommended survey weights.

Country-level measures of food provisioning systems include retail concentration and net trade. The retail concentration measure is the HerfindahlHirschman Index (HHI) and comes from the European Commission (2014). The HHI is calculated as the sum of squares of the market share of retail firms, and it can range from zero (minimal concentration) to 10,000 (maximum concentration). In this study, retail concentration ranges from 53 (Romania) to 1,271 (Austria). Net trade is the value of all food exports minus the value of food imports; positive values indicate net food exporters, whereas negative values indicate net food importers. Data come from the U.N. Food and Agriculture Organization (2017) and represent net trade in euros. In 2010, net trade ranged from -20,435.30 EUR in the United Kingdom to 19,520.40 EUR in the Netherlands. ${ }^{5}$

\footnotetext{
${ }^{5}$ Only two of the country-level variables include observations for the four subnational
} 
Table 2: Descriptive Statistics and Correlations for Country-level Variables

\begin{tabular}{|c|c|c|c|c|c|c|c|c|c|c|c|}
\hline Variable & Mean & $\mathrm{SD}$ & Min & $\operatorname{Max}$ & & 1 & 2 & 3 & 4 & 5 & 6 \\
\hline \multicolumn{12}{|l|}{ Outcome variables } \\
\hline Concerns about chemical/tech risks & 2.80 & 0.71 & 1.00 & 4.00 & 1 & 1.00 & & & & & \\
\hline Concerns about biological risks & 2.67 & 0.79 & 1.00 & 4.00 & 2 & 0.75 & 1.00 & & & & \\
\hline \multicolumn{12}{|l|}{ Country-level variables } \\
\hline Food risks are unnatural & 3.24 & 0.18 & 3.00 & 3.70 & 3 & 0.12 & 0.05 & 1.00 & & & \\
\hline Retail concentration (HHI) & 590.55 & 338.11 & 53.00 & 1271.00 & 4 & -0.12 & -0.17 & 0.08 & 1.00 & & \\
\hline Net trade & -348.18 & 6793.34 & -20435.30 & 19520.40 & 5 & 0.01 & -0.02 & 0.06 & 0.18 & 1.00 & \\
\hline Media coverage & 2.95 & 0.31 & 2.33 & 3.56 & 6 & 0.03 & 0.00 & 0.29 & 0.19 & 0.04 & 1.00 \\
\hline
\end{tabular}

The final contextual factor is media coverage of food risks, which is measured at the individual level (see above). Descriptive statistics for all countrylevel variables are in Table 2.

\section{Analytic strategy}

I use multi-level models to simultaneously estimate the influence of individual and contextual factors on food risk concerns (Raudenbush and Bryk 2001; Snijders and Bosker 1994). Multi-level models are recommended when predictors occur at different levels of aggregation (i.e., individual- and countrylevel). Multi-level modeling allows us to disentangle variation in risk concern within nations (micro-level effects) from cross-national variations (macro-level effects). Whereas standard OLS regressions assume that individual residuals are independent, multi-level models allow residuals to be correlated within nations. In mixed-effects models, random effects allow the slope of individuallevel predictors (e.g., institutional trust) to vary across higher-level units (i.e., country), allowing us to test whether the relationship varies cross-nationally. The data in this analysis are organized hierarchically, with 21,111 individuals nested in 28 subsamples from 26 countries. (Separate samples are collected from Northern Ireland, Great Britain, and from the former East and West Germany.) The analysis is conducted with the multi-level mixed-effects linear regression package in Stata 13. I begin with a random-effects model to determine the proportion of variance that is explained by country-level effects. Then I estimate mixed-effects models with the explanatory variables described above.

The models contain two parts: a level-one and country-level model. The level-one model estimates the average level of risk concern net of individual

samples (Northern Ireland, Great Britain, and East and West Germany): "unnaturalness" and media coverage. For retail concentration and net trade, national data from the U.K. and Germany are applied to the subsamples. 
characteristics, with standard errors clustered by country. The level-one models are represented by the following equation:

$$
\begin{array}{r}
Y_{i j}=\beta_{0 j}+\sum \beta_{(1-10) j} D E M O G+\sum \beta_{(11-12) j} C O N T R O L \\
+\sum \beta_{(13-21) j} T R U S T+\beta_{22 j} M E D I A+r_{i j}
\end{array}
$$

where $Y_{i j}$ is one of two constructs of food risk concern for person $i$ in country $j, \beta_{(1-22) j}$ are coefficients for individual-level predictors, and $r_{i j}$ is the random individual effect. For the outcome concerns about biological risks, two level-one coefficients vary cross-nationally and are estimated as random: institutional performance and control over biological risks. For the model of concerns about chemical/technical risks, coefficients for institutional performance and control over chemical/technical risks are estimated as random.

To explore contextual influences on individual food risk concerns, I then estimate the effects of country-level variables on the intercepts from the levelone models. The country-level models take the following form:

$$
\begin{array}{r}
\beta_{0 j}=\gamma_{00}+\gamma_{01} U N N A T U R A L+\gamma_{02} R E T A I L+\gamma_{03} T R A D E \\
+\gamma_{04} M E D I A+u_{0 j}
\end{array}
$$

where $\beta_{0 j}$ is the intercept in Eq. 1, $\gamma_{01-04}$ are coefficients for country-level predictors, and $u_{0 j}$ is the random country effect.

\section{RESULTS}

The analysis begins by estimating random-effects models for each outcome and calculating the intraclass correlation coefficients (ICC). Random-effects models contain no predictors and evaluate whether outcomes are sufficiently clustered to warrant multilevel analysis. The biological model has an ICC of $8.6 \%$, meaning that $8.6 \%$ of the total variation in individual concerns is accounted for at the country-level. A likelihood-ratio test indicates the superior fit of the two-level model over a single-level regression that does not account for nationality $\left(\chi^{2}=2452.14, p<.001\right)$. The random-effects model for chemical/technical risk concerns has an ICC of $7.3 \%$, and the likelihood-ratio test also supports a two-level model structure $\left(\chi^{2}=1946.28, p<.001\right)$. These tests indicate that individual concerns about biological and chemical/technical food risks vary significantly across countries. 


\section{Individual effects on food risk concern}

Table 3 displays results from the multilevel models. Results generally confirm previous findings about individual predictors of risk concern. Women worry more than men about both kinds of food risks, as has been previously reported (Dosman et al. 2001). Being married also increases the likelihood of concern. Prior research is mixed about the effect of children on food risk concerns (Dosman et al. 2001; Miles et al. 2004), and this analysis finds a positive but non-significant effect. Unlike previous studies, which estimate only a linear age effect (c.f. De Jonge et al. 2007), results show a significant quadratic effect for age $(p<.001)$. Concerns about both food risks increase significantly with age until respondents are in their 50s, after which concerns tend to decline. This trend does not match "objective" health risks, at least for microbial risks; the elderly are among the groups most vulnerable to foodborne illness.

Being a manager or professional significantly reduces concerns about biological risks but has no significant effect on chemical/technical risk concerns. People who have difficulty paying bills are significantly more likely to worry about both food risks, perhaps because they have fewer resources to spend on safer food. Urban residence is significantly related to chemical/technical but not biological food concerns; urban dwellers worry less than rural dwellers about chemical/technical risks. Interestingly, education has a significant effect on both outcomes but in opposite directions. As education increases, respondents report significantly fewer concerns about biological risks but greater concerns about chemical/technical risks. Continuing students follow the same pattern; students worry less about biological risks and more about chemical/technical risks than non-students. The divergent impact of education on food risk concerns merits further investigation.

The models also test predictions about individual influences on food risk concerns (hypotheses 1-3 above). Hypothesis 1, which predicts that perceived personal control reduces risk concerns, finds mixed support. Perceived control over biological and chemical/technical risks are both associated with reduced concerns about chemical/technical concerns. However, for concerns about biological risks, perceived control over biological risks shows the predicted effect while perceived control over chemical/technical risks increases predicted risk concern. It is not immediately obvious why this might be the case. Hypothesis 2 predicts that individuals perceive greater control over biological food risks than chemical/technical risks, and findings confirm this hypothesis. The mean score for perceived control over biological risks (2.44) is significantly higher than perceived control over chemical/technical risks (mean: $2.21 ; t=7.93, p$ $<.001)$. 
Table 3: Regression Coefficients for Multi-level Models of Food Risk Concern

\begin{tabular}{|c|c|c|}
\hline & Biological Risks & Chem/Tech Risks \\
\hline \multicolumn{3}{|l|}{ Fixed effects - individual level } \\
\hline Female & $\begin{array}{c}0.146^{* * *} \\
(0.01)\end{array}$ & $\begin{array}{c}0.155^{* * *} * \\
(0.01)\end{array}$ \\
\hline Married & $\begin{array}{c}0.048^{* * * *} \\
(0.01)\end{array}$ & $\begin{array}{c}0.047^{* * * *} \\
(0.01)\end{array}$ \\
\hline Children & $\begin{array}{l}0.020 \\
(0.01)\end{array}$ & $\begin{array}{l}0.020 \\
(0.01)\end{array}$ \\
\hline Education & $\begin{array}{c}-0.005^{* * *} \\
(0.00)\end{array}$ & $\begin{array}{c}0.002^{*} \\
(0.00)\end{array}$ \\
\hline Student & $\begin{array}{c}-0.155^{* * *} * \\
(0.03)\end{array}$ & $\begin{array}{l}0.050 \\
(0.03)\end{array}$ \\
\hline Manager/professional & $\begin{array}{c}-0.032^{* *} \\
(0.01)\end{array}$ & $\begin{array}{r}-0.002 \\
(0.01)\end{array}$ \\
\hline Age & $\begin{array}{c}0.010^{* * *} \\
(0.00)\end{array}$ & $\begin{array}{c}0.019^{* * * *} \\
(0.00)\end{array}$ \\
\hline Age*age & $\begin{array}{c}-0.0001^{* * *} \\
(0.00)\end{array}$ & $\begin{array}{c}-0.0002^{* * * *} \\
(0.00)\end{array}$ \\
\hline Difficulty paying bills & $\begin{array}{c}0.098^{* * *} \\
(0.00)\end{array}$ & $\begin{array}{c}0.070^{* * *} \\
(0.01)\end{array}$ \\
\hline Urban & $\begin{array}{r}-0.013 \\
(0.01)\end{array}$ & $\begin{array}{c}-0.033^{* * *} \\
(0.01)\end{array}$ \\
\hline \multicolumn{3}{|l|}{ Perceived personal control } \\
\hline Biological risks & $\begin{array}{c}-0.107^{* * *} \\
(0.02)\end{array}$ & $\begin{array}{c}-0.026 * * * \\
(0.01)\end{array}$ \\
\hline Chemical risks & $\begin{array}{c}0.036^{* * * *} \\
(0.01)\end{array}$ & $\begin{array}{c}-0.032^{*} \\
(0.02)\end{array}$ \\
\hline \multicolumn{3}{|l|}{ Actor-specific trust } \\
\hline EU institutions & $\begin{array}{c}0.016^{*} \\
(0.01)\end{array}$ & $\begin{array}{c}-0.004 \\
(0.01)\end{array}$ \\
\hline National government & $\begin{array}{c}-0.019^{* *} \\
(0.01)\end{array}$ & $\begin{array}{c}-0.028^{* * *} \\
(0.01)\end{array}$ \\
\hline Farmers & $\begin{array}{l}-0.005 \\
(0.01)\end{array}$ & $\begin{array}{l}0.001 \\
(0.01)\end{array}$ \\
\hline Manufacturers & $\begin{array}{l}0.006 \\
(0.01)\end{array}$ & $\begin{array}{c}-0.046^{* * *} \\
(0.01)\end{array}$ \\
\hline Retailers & $\begin{array}{c}-0.028^{* * *} \\
(0.01)\end{array}$ & $\begin{array}{c}-0.046^{* * *} \\
(0.01)\end{array}$ \\
\hline Environmental orgs & $\begin{array}{c}0.098^{* * * *} \\
(0.01)\end{array}$ & $\begin{array}{c}0.122^{* * * *} \\
\quad(0.01)\end{array}$ \\
\hline Consumer orgs & $\begin{array}{c}-0.020^{*} \\
(0.01)\end{array}$ & $\begin{array}{l}0.001 \\
(0.01)\end{array}$ \\
\hline Media & $\begin{array}{c}0.034^{* * *} \\
(0.01)\end{array}$ & $\begin{array}{l}0.004 \\
(0.01)\end{array}$ \\
\hline General trust in institutional performance & $\begin{array}{c}-0.045^{* * *} \\
(0.01)\end{array}$ & $\begin{array}{c}-0.074 * * * \\
(0.01)\end{array}$ \\
\hline Media coverage & $\begin{array}{c}0.048^{* * *} \\
(0.01)\end{array}$ & $\begin{array}{c}0.072^{* * *} \\
(0.01)\end{array}$ \\
\hline \multicolumn{3}{|l|}{ Fixed effects - country level } \\
\hline Food risks are unnatural & $\begin{array}{c}0.100 \\
(0.17)\end{array}$ & $\begin{array}{c}0.241^{*} \\
(0.12)\end{array}$ \\
\hline Retail concentration & $\begin{array}{c}-0.0003^{* * *} \\
(0.00)\end{array}$ & $\begin{array}{c}-0.0002^{* *} \\
(0.00)\end{array}$ \\
\hline Net trade & $\begin{array}{c}0.0000 \\
(0.00)\end{array}$ & $\begin{array}{c}0.0000 \\
(0.00)\end{array}$ \\
\hline Media coverage & $\begin{array}{l}0.120 \\
(0.11)\end{array}$ & $\begin{array}{l}0.081 \\
(0.07)\end{array}$ \\
\hline Intercept & $\begin{array}{c}2.013^{* * *} * \\
(0.56)\end{array}$ & $\begin{array}{c}1.544^{* * * *} \\
(0.40)\end{array}$ \\
\hline \multicolumn{3}{|l|}{ Random effects standard deviations } \\
\hline Country (intercept) & 0.196 & 0.145 \\
\hline Perceived control - bio (slope) & 0.082 & \\
\hline Perceived control - chem (slope) & & 0.076 \\
\hline Trust in insitutional performance (slope) & 0.043 & 0.037 \\
\hline
\end{tabular}



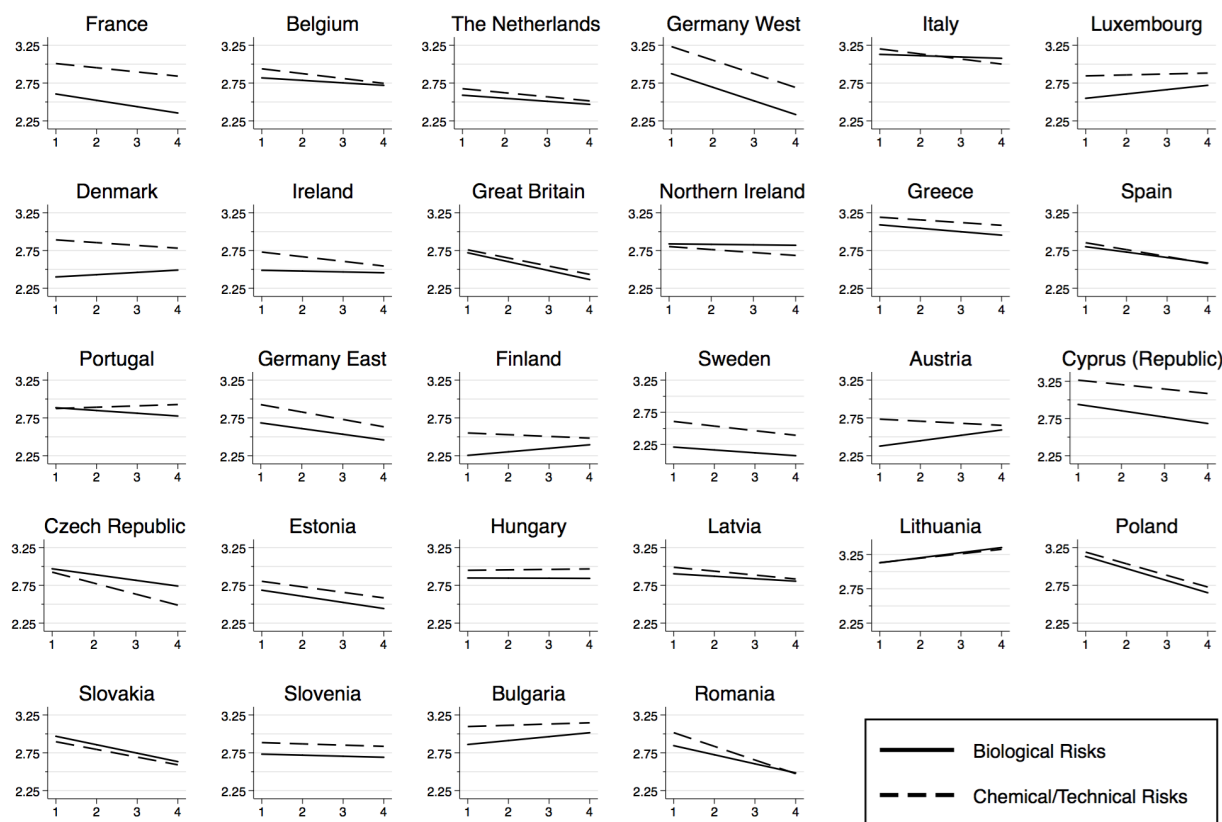

Note: Lines represent predicted mean of risk concern at different levels of insitutional trust, adjusting for other individual predictors. Horizontal axis is institutional trust (range: $1-4,1=$ low trust). Vertical axis is risk concern (range: $1-4,1=$ low concern).

Figure 3: Institutional Trust and Concerns about Food Risks, by Nation

Hypothesis 3 predicts that institutional trust, measured as evaluations of institutional performance and actor-specific honesty, reduces public concerns about food risks. The findings for institutional performance support this hypothesis, with greater trust associated with lower concerns about both food risks. However, the effect of institutional performance varies significantly across countries. Figure 3 displays country-specific relationships between institutional performance and risk concerns (i.e., the slopes estimated as random), controlling for other individual predictors. Institutional trust has a negative impact on risk concerns in the majority of European countries, but in some places the relationship is positive (e.g., Northern Ireland and Lithuania). The strength of the relationship also varies cross-nationally, with a much stronger effect in West Germany and Romania than in Hungary and Slovenia, where the slope is almost flat. This observed variance demonstrates the importance of continued cross-national research on risk concerns.

Findings for the actor-specific honesty measures present mixed support for Hypothesis 3. Trust in some actors is associated with reduced concerns, some have no significant effect, and others are associated with heightened con- 
cerns. For biological risks, trust in one's national government, retailers, and consumer groups is significantly associated with lower risk concerns, net other predictors. The effects of trusting farmers and manufacturers are not significant, and trust in E.U. institutions, environmental groups, and the media is significantly associated with heightened concerns about food risks. Results for chemical/technical risks differ slightly: trust in national government, manufacturers, and retailers is associated with reduced risk concerns; the effects of trusting E.U. institutions, farmers, consumer groups, and the media are not significant; and trust in environmental groups is significantly associated with higher risk concerns.

These findings support previous claims about the contextuality of institutional trust; trust is not a generalized attitude but varies according to the institutional actor and dimension of trust being surveyed (Kjaernes et al. 2007). Honesty is the only trust dimension that the Eurobarometer surveys across multiple institutional actors, so additional data are necessary to determine whether other trust dimensions (e.g., actors' performance or values) have actor-specific effects. The finding that institutional trust in some actors increases public concerns is surprising and merits further investigation. The fact that environmental groups and the media often play a watchdog role may help explain their association with heightened concerns, but the association between trust in E.U. institutions and concerns about biological risks is less easily explained.

\section{Contextual effects on food risk concern}

Hypotheses 4-7 make predictions about contextual influences on food risk concerns. Findings support Hypothesis 4, which predicts that aggregate perceptions about food risks being "unnatural" increase concerns about chemical/technical but not biological risks. Net other factors, living in a country where GM foods are perceived to be more "fundamentally unnatural" significantly increases the likelihood of concern about chemical/technical risks (but not biological risks). However, it is worth remembering that this is a contextual effect. These data cannot show that individuals who perceive chemical/technical food risks to be unnatural are more concerned about these risks. Rather, the data test the effect of living in places where a greater share of the population perceives these risks to be unnatural, independent of one's own beliefs. Additional data are necessary to test the individual effect of perceived unnaturalness.

Results show mixed support for the hypotheses about industry-related influences on risk concern. Differences in net food imports are not significantly 
related to food risk concerns; this fails to support Hypothesis 5, which predicts that national food independence reduces individuals' food-related anxieties. However, findings support Hypothesis 6, which predicts that retail concentration is associated with reduced risk concerns. Countries with greater retail concentration report significantly lower concerns about both biological and chemical/technical risks, confirming results from a previous study on a smaller set of countries (Kjaernes et al. 2007). The explanation for the effect cannot be discerned from the data, although Kjaernes et al. (2007) suggest that consumers may associate the standardized, technological processes of large retailers with safety and predictability.

The last hypothesis addresses the influence of media coverage on food risk concerns. I estimate individual and contextual effects of media coverage to test whether individuals exposed to greater media coverage report increased concerns, as well as whether individuals living in countries with greater media coverage report elevated concerns independent of their own exposure. I find a strong positive effect of individual media exposure but no significant contextual effect. Individuals who remember more recent coverage of food risks report heightened concerns about both outcomes, but living in a country with greater media coverage does not additionally increase risk concerns, net other controls.

\section{DISCUSSION AND CONCLUSION}

This paper demonstrates that food-related concerns are strong but varied across Europe and identifies several contextual influences. Findings indicate that national variations in food risk concern can be partly explained by aggregate differences in perceived "unnaturalness" of chemical/technical risks, retail concentration in the food sector, and media coverage of food risks. Causal conclusions cannot be drawn from these findings, but results do suggest that public risk concerns are related not only to individual characteristics but also to institutional factors that vary cross-nationally. These findings contribute to research on the contextuality of public risk concerns, emphasizing the role of national food provisioning systems and civic society in shaping public expectations and concerns (Kjaernes et al. 2007).

This paper uses a multi-level modeling strategy on data from 26 European countries to test predictions from previous cross-national research. Like past studies, the results show that individual-level factors contribute to variations in food risk concern. Gender, marital status, age, and socioeconomic status are significantly related to individual concerns over biological and chem- 
ical/technical food risks. Perceived control over food risks is significantly associated with lower levels of concern about chemical/technical risks, in line with previous findings (Renn et al. 1992; Slovic 1987). However, the relationship between perceived control and concerns about biological food risks depends on the risk being controlled; perceived control over biological risks reduces concerns, but perceived control over chemical/technical risks increases concerns. Interestingly, the results indicate that the effect of education also varies by food risk type; higher levels of education are associated with reduced concerns over biological food risks but heightened concerns over chemical/technical risks. The inconsistent effects of education and perceived personal control require further examination.

Institutional trust is a well-studied predictor of risk concerns across a range of hazard domains, yet few studies have considered how the effect of institutional trust varies across national contexts or risk type. This paper shows that the effect of trust on food risk concerns varies substantially across European countries, controlling for other individual predictors. Institutional trust has a strongly negative effect on food risk concerns in some countries, while in others the effect is weakened or even positive. Even within the same country, the effect of institutional trust can vary across concerns over biological and chemical/technical food risks. These findings should caution researchers against universal explanations of risk perception and encourage more comparative analyses on the contextual bases of risk concerns.

A further sign of the contextuality of institutional trust is the varying influence of actor-specific trust measures on food risk concerns. The analysis includes eight actor-specific honesty measures for national and international governments, food industry actors, civic organizations, and the media. Findings suggest substantial variation in the effect of institutional honesty on food risk concerns: trust in some actors (e.g., retailers) significantly reduces risk concerns, trust in others (e.g., environmental organizations) significantly raises risk concerns, and still others (e.g., farmers) appear much less impactful on public risk concerns. Furthermore, the effect of some institutional actors varies by food risk type. For example, trust in manufacturers significantly reduces concerns about chemical/technical risks but not biological risks. Risk managers often talk about the importance of building trust for mitigating public risk concerns, yet this study shows that the effectiveness of such efforts is likely to depend on the national context, risk type, and institutional actor. Some institutional actors appear to matter more in certain risk contexts, and building trust in some actors (e.g., environmental organizations) may even be counterproductive in efforts to reduce public concerns.

Comparing the correlates of concern across the two risk domains in the 
study (biological and chemical/technical food risks), we can discern a few important differences. Education has a different effect on chemical/technical and biological risk concerns, as does the effect of perceived control over chemical/technical risks (as discussed above). Additionally, concerns about chemical/technical risks appear significantly related to aggregate perceptions of "unnaturalness," unlike biological risk concerns. However, it is not clear the extent to which these differences explain why chemical/technical food risks are the subject of extensive public controversy in Europe while biological risks remain a more individualized concern. Findings indicate that Europeans do worry significantly more about chemical/technical risks than biological ones, which they perceive to be more personally controllable. Yet Europeans' concerns about biological food risks are not low, and by and large the individual and contextual influences on both risk concerns trend in the same direction. Therefore, it may be that the divergent public treatment of biological and chemical/technical food risks is less a function of individual attitudes than of the social organization of public opinion. It is well-established that public risk concerns are framed by the media and other institutional actors (Freudenburg and Pastor 1992; Lockie 2006), and it is worth exploring how different food risks are rhetorically positioned in relation to other public concerns about health, food cultures, and institutional responsibility. Results on the effects of perceived "unnaturalness" and personal control may be one clue about their divergent framing; if biological food risks are framed as more natural and personally controllable than other types of food risks, then individuals and civic organizations may be less inclined to see them as appropriate targets for collective mobilization.

This paper raises several important questions for future research. For example, additional research is necessary to understand the mechanisms by which contextual factors influence risk concerns and the likely interactions between different institutional domains. Given previous research on the "embeddedness" of markets in social institutions (Granovetter 1985), it might be fruitful to explore how the influence of retail concentration on risk concerns is related to organizational dynamics in the state or other social institutions. The likely interrelated and interacting nature of these contextual factors should make us wary of any universal policy prescriptions; much more research is necessary to determine how and why different contextual factors influence national risk concerns, and it is likely that the magnitude of the effects differs cross-nationally for important social and historical reasons.

Continued cross-national research on risk perception is important for improving our understanding of individual and institutional influences on risk concern. Until now, most cross-national research on European food-related 
concerns has focused on a small number of countries, producing many important insights but prompting questions about generalizability. In a separate analysis (not shown but available upon request), I estimate separate OLS regressions for each country in the sample using the same set of individual predictors as in the main analysis, and results show large variations in model goodness-of-fit. For the national models of concerns about chemical/technical risks, the $R^{2}$ measures range from .06 in Bulgaria to .29 in the Netherlands, meaning the model accounts for nearly five times the variance in Dutch risk concerns as it does for Bulgarian concerns. For the national models of concerns about biological food risks, the $R^{2}$ values range from .07 in Romania to .19 in Denmark. These results suggest that current theories about risk perception may be better suited to societies in Northern and Western Europe than to newer E.U. member states in Eastern Europe. Additionally, the models seem to explain more variance in concerns over chemical/technical risks than concerns over biological risks. That previous cross-national work on risk perception has tended to survey societies in Northern and Western Europe about chemical/technical risks has likely contributed to this difference. Further comparative research is necessary to develop more refined understandings of public risk perception that generalize beyond the most-studied countries and risk domains.

This paper demonstrates substantial variations in risk concerns across 26 European countries and two domains of food-related risk (chemical/technical and biological), arguing that individual and contextual factors contribute to these variations. The findings demonstrate support for several predictions gleaned from previous comparative studies, yet more research is necessary to understand the mechanisms behind the contextual effects and the explanations for why some effects are stronger in certain countries than in others.

\section{REFERENCES}

Ansell, Christopher, Rahsaan Maxwell, and Daniela Sicurelli. 2006. "Protesting Food: NGOs and Political Mobilization in Europe." in What's the Beef?: The Contested Governance of European Food Safety.

Baiardi, Donatella, Riccardo Puglisi, and Simona Scabrosetti. 2016. "Individual Attitudes on Food Quality and Safety: Empirical Evidence on EU Countries." Food Quality and Preference 49:70-74.

Berg, Lisbet et al. 2005. "Trust in Food Safety in Russia, Denmark and Norway." European Societies 7(1):103-29. 
Costa-Font, Montserrat and José M. Gil. 2009. "Structural Equation Modelling of Consumer Acceptance of Genetically Modified (GM) Food in the Mediterranean Europe: A Cross Country Study." Food Quality and Preference 20(6):399-409.

De Jonge, Janneke, Hans Van Trijp, Reint Jan Renes, and Lynn Frewer. 2007. "Understanding Consumer Confidence in the Safety of Food: Its Two-Dimensional Structure and Determinants." Risk Analysis 27(3):72940.

De Jonge, J., J. C. M. Van Trijp, I. A. Van der Lans, R. J. Renes, and L. J. Frewer. 2008. "How Trust in Institutions and Organizations Builds General Consumer Confidence in the Safety of Food: A Decomposition of Effects." Appetite 51(2):311-17.

Dosman, D. M., W. L. Adamowicz, and S. E. Hrudey. 2001. "Socioeconomic Determinants of Health- and Food Safety-Related Risk Perceptions." Risk Analysis 21(2):307-17.

Elliott, Gregory R. and Ross C. Cameron. 1994. "Consumer Perception of Product Quality and the Country-of-Origin Effect." Journal of International Marketing 2(2):49-62.

European Commission. 2010a. Eurobarometer 73.1: The European Parliament, Biotechnology, and Science and Technology.

European Commission. 2010b. Eurobarometer 73.5: Civil Justice, Development Aid, Africa and the European Union, and Food Risk.

European Commission. 2014. The Economic Impact of Modern Retail on Choice and Innovation in the EU Food Sector.

Fife-Schaw, Chris and Gene Rowe. 1996. "Public Perceptions of Everyday Food Hazards: A Psychometric Study." Risk Analysis 16(4):487-500.

Freudenburg, William R. 1993. "Risk and Recreancy: Weber, the Division of Labor, and the Rationality of Risk Perceptions." Social Forces 71(4):90932 .

Freudenburg, William R. and Susan K. Pastor. 1992. "Public Responses to Technological Risks." The Sociological Quarterly 33(3):389-412.

Frewer, L. J., C. Howard, D. Hedderley, and R. Shepherd. 1996. "What Determines Trust in Information About Food-Related Risks? Underlying 
Psychological Constructs." Risk Analysis 16(4):473-86.

Frewer, Lynn J., Richard Shepherd, and Paul Sparks. 1994. "The Interrelationship Between Perceived Knowledge, Control and Risk Associated with a Range of Food-Related Hazards Targeted at the Individual, Other People and Society." Journal of Food Safety 14(1):19-40.

Gaskell, George, Katrin Hohl, and Monica M. Gerber. 2016. "Do Closed Survey Questions Overestimate Public Perceptions of Food Risks?" Journal of Risk Research 0(0):1-15.

Giddens, Anthony. 1990. The Consequences of Modernity. Stanford, CA: Stanford University Press.

Graham, John W., Allison E. Olchowski, and Tamika D. Gilreath. 2007. "How Many Imputations Are Really Needed? Some Practical Clarifications of Multiple Imputation Theory." Prevention Science 8(3):206-13.

Granovetter, Mark. 1985. "Economic Action and Social Structure: The Problem of Embeddedness." American Journal of Sociology 91(3):481-510.

Hansen, Janus, Lotte Holm, Lynn Frewer, Paul Robinson, and Peter Sandøe. 2003. "Beyond the Knowledge Deficit: Recent Research into Lay and Expert Attitudes to Food Risks." Appetite 41(2):111-21.

Henderson, Julie, Paul Ward, John Coveney, and Samantha Meyer. 2012. "Trust in the Australian Food Supply: Innocent Until Proven Guilty." Health, Risk \& Society 14(3):257-72.

Henderson, Julie et al. 2014. "The Role of the Media in Construction and Presentation of Food Risks." Health, Risk $\&$ Society 16(7-8):615-30.

Hoffmann, Ruben. 2000. "Country of Origin - a Consumer Perception Perspective of Fresh Meat." British Food Journal 102(3):211-29.

Hohl, Katrin and George Gaskell. 2008. "European Public Perceptions of Food Risk: Cross-National and Methodological Comparisons." Risk Analysis 28(2):311-24.

Hunt, Stephen and Lynn J. Frewer. 2001. "Impact of BSE on Attitudes to GM Food." Risk, Decision and Policy 6(2):91-103.

Jasanoff, Sheila. 1997. "Civilization and Madness: The Great BSE Scare of 1996." Public Understanding of Science 6(3):221-32. 
Kher, Swaroop V. et al. 2013. "Consumer Perceptions of Risks of Chemical and Microbiological Contaminants Associated with Food Chains: A CrossNational Study." International Journal of Consumer Studies 37(1):73-83.

Kjaernes, U., Mark Harvey, and Alan Warde. 2007. Trust in Food: A Comparative and Institutional Analysis. New York: Palgrave Macmillan.

Kjaernes, Unni. 2006. "Trust and Distrust: Cognitive Decisions or Social Relations?" Journal of Risk Research 9(8):911-32.

Lang, John T. 2013. "Elements of Public Trust in the American Food System: Experts, Organizations, and Genetically Modified Food." Food Policy $41: 145-54$.

Lang, John T. and William K. Hallman. 2005. "Who Does the Public Trust? The Case of Genetically Modified Food in the United States." Risk Analysis 25(5):1241-52.

Lobb, Alexandra. 2005. "Consumer Trust, Risk and Food Safety: A Review." Food Economics - Acta Agriculturae Scandinavica, Section C 2(July 2014):3-12.

Lobb, Alexandra E. and Mario Mazzocchi. 2007. "Domestically Produced Food: Consumer Perceptions of Origin, Safety and the Issue of Trust." Acta Agriculturae Scandinavica, Section C-Food Economics 4(1):3-12.

Lockie, Stewart. 2006. "Capturing the Sustainability Agenda: Organic Foods and Media Discourses on Food Scares, Environment, Genetic Engineering, and Health." Agriculture and Human Values 23(3):313-23.

Marques, Mathew D., Christine R. Critchley, and Jarrod Walshe. 2015. "Attitudes to Genetically Modified Food over Time: How Trust in Organizations and the Media Cycle Predict Support." Public Understanding of Science 24(5):601-18.

Miles, Susan et al. 2004. "Public Worry About Specific Food Safety Issues." British Food Journal 106(1):9-22.

Miles, Susan and Lynn J. Frewer. 2001. "Investigating Specific Concerns About Different Food Hazards." Food Quality and Preference 12(1):47-61.

Poortinga, Wouter and Nick F. Pidgeon. 2003. "Exploring the Dimensionality of Trust in Risk Regulation." Risk Analysis 23(5):961-72. 
Raudenbush, Stephen W. and Anthony S. Bryk. 2001. Hierarchical Linear Models: Applications and Data Analysis. 2nd ed. Newbury Park, CA: Sage Publications.

Renn, Ortwin, William J. Burns, Jeanne X. Kasperson, Roger E. Kasperson, and Paul Slovic. 1992. "The Social Amplification of Risk: Theoretical Foundations and Empirical Applications." Journal of Social Issues 48(4):137-60.

Renn, Ortwin and Bernd Rohrmann. 2013. Cross-Cultural Risk Perception: A Survey of Empirical Studies. Springer Science \& Business Media.

Schurman, Rachel. 2014. "Fighting 'Frankenfoods': Industry Opportunity Structures and the Efficacy of the Anti-Biotech." Social Problems 51(2):24368.

Siegrist, Michael and George Cvetkovich. 2000. "Perception of Hazards: the Role of Social Trust and Knowledge." Risk Analysis 20(5):713-20.

Siegrist, Michael, Heinz Gutscher, and Timothy C. Earle. 2005. "Perception of Risk: The Influence of General Trust, and General Confidence." Journal of Risk Research 8(2):145-56.

Siegrist, Michael, Nathalie Stampfli, Hans Kastenholz, and Carmen Keller. 2008. "Perceived Risks and Perceived Benefits of Different Nanotechnology Foods and Nanotechnology Food Packaging." Appetite 51(2):283-90.

Sjöberg, Lennart. 2000. "Perceived Risk and Tampering with Nature." Journal of Risk Research 3(4):353-67.

Slovic, P. 1987. "Perception of Risk." Science 236(4799):280-85.

Slovic, Paul. 1993. "Perceived Risk, Trust, and Democracy." Risk Analysis 13(6):675-82.

Slovic, Paul. 2013. Risk, Media and Stigma: Understanding Public Challenges to Modern Science and Technology. Routledge.

Snijders, Tom A. B. and Roel J. Bosker. 1994. "Modeled Variance in TwoLevel Models." Sociological Methods 86 Research 22(3):342-63.

Sparks, Paul and Richard Shepherd. 1994. "Public Perceptions of the Potential Hazards Associated with Food Production and Food Consumption: An Empirical Study." Risk Analysis 14(5):799-806. 
U.N. FAO. 2017. FAOSTAT.

Von Hippel, Paul T. 2007. "Regression with Missing Ys: An Improved Strategy for Analyzing Multiply Imputed Data." Sociological Methodology 37(1):83-117.

White, Ian R., Patrick Royston, and Angela M. Wood. 2011. "Multiple Imputation Using Chained Equations: Issues and Guidance for Practice." Statistics in Medicine 30(4):377-99.

Wohlers, Anton E. 2010. "Regulating Genetically Modified Food." Politics and the Life Sciences 29(2):17-39.

Zucker, Lynne. 1985. "Production of Trust: Institutional Sources of Economic Structure, 1940 to 1920." in Research in Organizations, vol. 8. Greenwich, CT: JAI Press. 